\title{
Clinical presentations, diagnosis, mortality and prognostic markers of tuberculous meningitis in Vietnamese children: a prospective descriptive study
}

Nguyen Duc Bang ${ }^{1,2}$, Maxine Caws ${ }^{1,3,4}$, Thai Thanh Truc ${ }^{1}$, Tran Ngoc Duong ${ }^{2}$, Nguyen Huy Dung ${ }^{2}$, Dang Thi Minh Ha ${ }^{1,2}$, Guy E. Thwaites ${ }^{1,4}$, Doortje Heemskerk ${ }^{1,4}$, Joel Tarning ${ }^{4,5}$, Laura Merson ${ }^{1,4}$, Pham Van Toi ${ }^{1,4}$, Jeremy J. Farrar ${ }^{1,4}$, Marcel Wolbers ${ }^{1,4}$, Thomas Pouplin ${ }^{1,4,5}$ and Jeremy N. Day ${ }^{1,4^{*}}$

\begin{abstract}
Background: Tuberculous meningitis in adults is well characterized in Vietnam, but there are no data on the disease in children. We present a prospective descriptive study of Vietnamese children with TBM to define the presentation, course and characteristics associated with poor outcome.

Methods: A prospective descriptive study of 100 consecutively admitted children with TBM at Pham Ngoc Thach Hospital, Ho Chi Minh City. Cox and logistic regression were used to identify factors associated with risk of death and a combined endpoint of death or disability at treatment completion.

Results: The study enrolled from October 2009 to March 2011. Median age was 32.5 months; sex distribution was equal. Median duration of symptoms was 18.5 days and time from admission to treatment initiation was 11 days. Fifteen of 100 children died, 4 were lost to follow-up, and 27/81 (33\%) of survivors had intermediate or severe disability upon treatment completion. Microbiological confirmation of disease was made in $6 \%$. Baseline characteristics associated with death included convulsions ( $H R 3.46,95 \mathrm{Cl} 1.19-10.13, p=0.02$ ), decreased consciousness (HR 22.9, 95Cl 3.01-174.3, $p<0.001$ ), focal neurological deficits (HR 15.7, 95Cl 1.67-2075, $p=0.01$ ), Blantyre Coma Score (HR 3.75, 95CI 0.99-14.2, p < 0.001) and CSF protein, lactate and glucose levels. Neck stiffness, MRC grade (children aged $>5$ years) and hydrocephalus were also associated with the combined endpoint of death or disability.
\end{abstract}

Conclusions: Tuberculous meningitis in Vietnamese children has significant mortality and morbidity. There is significant delay in diagnosis; interventions that increase the speed of diagnosis and treatment initiation are likely to improve outcomes.

Keywords: Tuberculous meningitis, Children, Vietnam, Mycobacterium, Survival

\footnotetext{
* Correspondence: jday@oucru.org

'Oxford University Clinical Research Unit, Wellcome Trust Major Overseas

Programme, 764 Vo Van Kiet, Quan 5, Ho Chi Minh City, Vietnam

${ }^{4}$ Centre for Tropical Medicine and Global Health, Nuffield Department of

Medicine Research Building, University of Oxford, Old Road campus,

Roosevelt Drive, Oxford, UK

Full list of author information is available at the end of the article
} 


\section{Background}

Tuberculosis (TB) is an important cause of childhood morbidity - recent estimates of the number of children developing TB each year range from 500000 to 1 million, significantly higher than previously estimated by the WHO [1, 2]. There may be 50 million children latently infected [3]. $5 \%$ of disease occurs in HIV coinfected children, although this is higher in sub-Saharan Africa [3]. Despite this high burden, in TB as in many other diseases, children are a neglected group - the vast majority of data used to guide management are derived from adult patients.

Tuberculous meningitis (TBM) is the most severe form of tuberculosis, with high rates of disability and death [4]. Children are more likely than adults to develop disseminated TB and TB meningitis following infection [5]. This risk is greatest for infants and children under 2 years of age, probably due to the immaturity of the immune system [6]. The challenges of TBM diagnosis and management are exacerbated in children. Initial symptoms in infants are non-specific, it is difficult to obtain diagnostic samples and more invasive sampling methods are needed, and the diagnostics samples obtained generally proffer extremely low yields of mycobacteria [7, 8]. Death from TBM is strongly associated with delays in diagnosis and treatment both in children and adults [9-12]. It is striking that there has never been a randomized controlled trial of anti-tuberculosis drugs in children with TBM [13].

Vietnam is classified as having a high burden of TB, with a prevalence in the order of 145 per 100000 of the population as a whole [14]. Tuberculous meningitis in adults is well characterized in Vietnam, and these data have been key in developing treatment guidelines, but there are no data on the disease in children [11, 15-17]. In accordance with historic WHO policy, the Vietnamese National TB Programme has focused on the systematic notification of smear positive cases of TB. However, the majority of pediatric TB cases are smear negative, and subsequently limited data are available on pediatric TB in Vietnam. In line with WHO policy revisions, Vietnam has recently implemented disaggregated data collection for pediatric TB. Improving outcomes in children is dependent upon a better understanding of the epidemiology of childhood TB, and early diagnosis and instigation of effective treatment.

\section{Methods}

\section{Study aim}

This study aimed to describe the current practice in the management of Vietnamese children with TBM, the presenting clinical features and predictors of poor outcome (death and neurological disability), in order to define the challenges in management and prioritise research.

\section{Study design}

A prospective descriptive study of 100 consecutive cases of TBM in children (aged $\leq 15$ years).

\section{Setting and participants}

The study was conducted at Pham Ngoc Thach Hospital (PNT), Ho Chi Minh City (HCMC). PNT is the tertiary referral centre for tuberculosis in the south of Vietnam, serving 40 million people. All children diagnosed or suspected of having TBM in HCMC and the surrounding provinces are referred here. Approximately 500 inpatient cases of pediatric TB are treated each year; around $20 \%$ have meningitis.

\section{Entry criteria}

All patients aged $\leq 15$ years presenting to Pham Ngoc Thach Hospital with a clinical syndrome consistent with TBM (meaning one or more of: fever, headache, neck stiffness, vomiting, confusion, coma, convulsions, cranial nerve palsies, hemiplegia or paraplegia) and considered to have tuberculous meningitis by their attending physician (i.e. meriting anti-TB therapy) were eligible to enter the study. TBM was classified as "definite", "probable" or "possible", as follows:

Definite TBM: acid-fast bacilli (AFB) seen or cultured from cerebrospinal fluid (CSF).

Probable TBM: Clinical syndrome consistent with TBM, and one or more of the following criteria: suspected active pulmonary tuberculosis on chest radiography, AFB found in any specimen other than the CSF, brain imaging consistent with TBM, or clinical evidence of other extrapulmonary tuberculosis.

Possible TBM: Clinical syndrome consistent with TBM and at least 4 of the following: past medical history of tuberculosis, predominance of lymphocytes in the CSF, illness of $\geq 6$ days in duration, CSF: blood glucose ratio $<0.5$, altered consciousness, yellow CSF, and focal neurological signs.

\section{Patient assessment}

All patients had clinical assessments by the dedicated study team at study entry, 2 weeks, 1, 2, 3 and 8 months.

\section{Lumbar puncture}

All patients underwent lumbar puncture either at the referring centre or on admission to PNT hospital. Lumbar puncture was repeated at days 30 and 90 following study entry/treatment initiation. Cerebrospinal fluid (CSF) investigations included cell count, glucose, protein, lactate, Gram's stain, and India ink test, and culture for fungi and pyogenic bacteria. CSF Ziehl-Neelsen smear and culture were not available at referring centres. When patients were referred from other centres, lumbar puncture was 
only repeated at baseline if felt to be clinically indicated by the attending physician. The GeneXpert test was not available at the time the study took place.

\section{Other investigations}

All children had haematology and biochemistry investigations according to standard of care in the hospital. Sputum was examined for acid fast bacteria (AFB) when available; gastric washings for AFB were done at the discretion of the attending physician. All patients had HIV testing - counselling and HIV testing were available for the parents of children diagnosed with HIV. All patients had a chest radiograph performed at study entry. 40 patients were entered into a descriptive radiological substudy and underwent cranial Magnetic Resonance Imaging (MRI) at study entry, on day 60 and day 270 . Other imaging was performed at the discretion of the attending physician.

\section{Classification of severity}

All patients were graded for severity at study entry. For children older than 5 years severity was graded according to a modified United Kingdom Medical Research Council criteria based on Glasgow Coma Score: Grade I had a Glasgow coma score (GCS) of 15/15 with no focal neurological signs, grade II either had a GCS 11-14 or GCS 15 with focal neurological signs, Grade III had a GCS of $\leq 10$.

For children less than 5 years of age severity of TBM was graded according to the Blantyre Coma Score. Patients with grade I disease had a Blantyre coma score of 4-5 with no focal neurological signs; patients with grade II disease had a Blantyre coma score of 2-3 or a score of 4-5 with focal neurological signs; and grade III had a Blantyre coma score $\leq 1$.

\section{Treatment and follow-up}

Anti-tuberculosis treatment was according to Vietnamese treatment guidelines, which at the time were consistent with the 2006 WHO guidelines. Patients received oral isoniazid $(5 \mathrm{mg} / \mathrm{kg})$, rifampicin $(10 \mathrm{mg} / \mathrm{kg})$, pyrazinamide $(25 \mathrm{mg} / \mathrm{kg})$, ethambutol $15 \mathrm{mg} / \mathrm{kg}$ and intramuscular streptomycin $(15 \mathrm{mg} / \mathrm{kg})$ for 2 months, followed by oral isoniazid, rifampicin, pyrazinamide and ethambutol for 1 month and oral isoniazid, rifampicin, and ethambutol at the same doses for 5 months [2HRZES/1HRZE/ 5HRE]. Streptomycin was not used for HIV-infected patients. Patients with MRC grades II and III and BCS grades II and III disease received adjuvant dexamethasone for the first six weeks; patients with MRC grade I and BCS grade I received adjuvant dexamethasone for 4 weeks as per Vietnamese guidelines [11]. All patients were reviewed daily by the study team while in-patients, at days 30, 60 and 90, and on completion of treatment after 8 months. DOT was used to secure and monitor treatment adherence, and drugs were administered via nasogastric tube to unconscious children.

\section{Assessment of outcome}

We were interested in two outcomes: survival, and a combined endpoint of neurological disability or death. Disability status was assessed at the end of 8 months of treatment with the use of the two simple questions ("Does the child require help from anybody for everyday activities [e.g., eating, drinking, washing, brushing teeth, and going to the toilet]?" and "Has the illness left the child with any other problems?") and the modified Rankin scale (scores range from 0 [no symptoms at all] to 6 [death]) and was classified as good (i.e., no disability), intermediate, severe, or death, as described elsewhere [11]. For children under 5 years, the response was determined by the study clinician in relation to the expected functioning in normal children of the same age.

\section{Study size}

The study was designed as a prospective descriptive study to include all patients less than or equal to 15 years of age presenting with suspected TBM to Pham Ngoc Thach Hospital. Approximately 100 such patients are admitted each year, and we planned to recruit 100 consecutively admitted patients.

\section{Statistical analysis}

The raw data was imported into a secure anonymised in-house data management system (CliRes). Between group comparisons of baseline characteristics were based on the Wilcoxon rank sum test and Fisher's exact test for continuous and categorical variables, respectively. Mortality at 8 months was estimated with the Kaplan-Meier method. Univariate Cox regression was used to identify significant factors influencing time to death. Factors relating to the probability of a combined endpoint of neurological sequelae (intermediate or severe disability) or death were determined using univariate logistic regression and the Firth correction was applied in case of separation [18]. Multivariable regression models were not fitted due to the relatively low number of events and large number of factors of interest. All analyses were performed using $\mathrm{R}$ software version 2.9.1 [19].

\section{Results}

\section{Demographic and clinical characteristics}

Enrollment was conducted between October 2009 and March 2011. During this period 133 children were admitted to PNT hospital with suspected TBM. Twelve children declined to join the study and 21 were not recruited because they were already receiving treatment. 
Follow-up completed in December 2011. The median duration from first hospital admission to making the diagnosis of TBM (and instigation of treatment) was 11 days (range 1-74 days).

Baseline characteristics and outcomes for the cohort are shown in Table 1.

Fifty-six percent $(n=56 / 100)$ of patients were male. The majority of children (67\%) were less than 5 years old (median age 32.5 months, range 2 to 180 months). Four of 96 children tested were HIV infected (4\%); $5 \%$ $(n=5 / 96)$ were hepatitis B surface antigen positive. Concomitant extra-pulmonary TB was common, seen in 42 patients (36 pulmonary, 4 pulmonary with peripheral

Table 1 Baseline characteristics and outcomes of 100 childhood TBM patients

\begin{tabular}{|c|c|c|c|}
\hline $\begin{array}{l}\text { Symptoms and } \\
\text { signs }\end{array}$ & \multicolumn{2}{|c|}{ Number affected (\%) } & $\begin{array}{l}\text { Median duration in } \\
\text { days (range) }\end{array}$ \\
\hline Fever & \multicolumn{2}{|l|}{ 96/97 (99 \%) } & $23 ;(6-96)$ \\
\hline Vomiting & \multicolumn{2}{|l|}{ 76/100 (76 \%) } & $13 ;(1-96)$ \\
\hline Weight loss & \multicolumn{2}{|l|}{ 59/98 (60 \%) } & $15.5 ;(7-90)$ \\
\hline Confusion & \multicolumn{2}{|l|}{ 15/100 (15 \%) } & $10.4 ;(2-30)$ \\
\hline Unconsciousness & \multicolumn{2}{|l|}{ 27/100 (27 \%) } & $5.3 ;(1-16)$ \\
\hline Headache $^{a}$ & \multicolumn{2}{|l|}{ 49/55 (89 \%) } & $21 ;(4-66)$ \\
\hline Fits & \multicolumn{2}{|l|}{ 39/100 (39 \%) } & $8.5 ;(1-35)$ \\
\hline Neck stiffness & \multicolumn{2}{|l|}{ 75/100 (75 \%) } & \\
\hline $\begin{array}{l}\text { Hemiparesis/ } \\
\text { Hemiplegia }\end{array}$ & \multicolumn{2}{|l|}{ 20/98 (20 \%) } & \\
\hline $\begin{array}{l}\text { Paraparesis/ } \\
\text { paraplegia }\end{array}$ & \multicolumn{2}{|l|}{ 6/98 (6 \%) } & \\
\hline Monoplegia & \multicolumn{2}{|l|}{ 4/98 (4 \%) } & \\
\hline Quadriplegia & \multicolumn{2}{|l|}{ 2/98 (2 \%) } & \\
\hline $\begin{array}{l}\text { Il nerve } \\
\text { involvement }\end{array}$ & \multicolumn{2}{|l|}{ 3/98 (3 \%) } & \\
\hline III nerve palsy & \multicolumn{2}{|l|}{ 4/98 (4 \%) } & \\
\hline VI nerve palsy & \multicolumn{2}{|l|}{ 20/98 (20 \%) } & \\
\hline VII nerve palsy & \multicolumn{2}{|l|}{ 7/98 (7 \%) } & \\
\hline $\begin{array}{l}\text { Anemia } \\
(\mathrm{Hb}<11 \mathrm{~g} / \mathrm{dL})\end{array}$ & \multicolumn{2}{|l|}{ 46/99 (46 \%) } & \\
\hline HIV infection & \multicolumn{2}{|l|}{ 4/96 (4 \%) } & \\
\hline HBV infection & \multicolumn{2}{|l|}{ 5/96 (5 \%) } & \\
\hline $\begin{array}{l}\text { MRC Grades } \\
>5 \text { years }(33)\end{array}$ & I: 16 (48 \%) & II: 11 (33\%) & III: 6 (18 \%) \\
\hline $\begin{array}{l}\text { Blantyre }< \\
5 \text { years }(67)\end{array}$ & 4-5: $43(64 \%)$ & 2-3: 12 (18 \%) & 0-1: 12 (18 \%) \\
\hline Deaths & 15/100 (15 \%) & & \\
\hline \multicolumn{4}{|l|}{ Sequelae } \\
\hline Severe & \multicolumn{2}{|l|}{ 6/81 (7 \%) } & \\
\hline Intermediate & \multicolumn{2}{|l|}{$21 / 81$ (26 \%) } & \\
\hline
\end{tabular}

annable to ascertain in 44 due to the age of the child; headache was not assessed for one additional subject lymphadenitis, 1 pulmonary disease with pleural involvement, and 1 pulmonary disease with concomitant TB arthritis. A family history of TB was reported for 27 patients $(27 \%)$; one patient had a previous history of TB.

Fever, vomiting and nuchal rigidity were the most frequently elicited symptoms. Seizures were common reported in 39 cases. Headaches occurred in at least 49 (49 \%) cases - in 44 cases (44\%) the presence of headache was uncertain because the child was too young to describe the symptom. Of 33 (33\%) children $\geq 5$ years of age, 16 (48 \%) had MRC grade I disease, 11 (33\%) grade II disease, and 6 (18 \%) grade III disease. The remaining 67 children under 5 years were graded using the Blantyre coma score (BCS): BCS I (4-5): 43 (64\%), BCS II (2-3): 12 (18 \%) and BCS III (0-1): 12 (18 \%) (Table 1). Focal neurological signs were frequent occurring in $58 \%$, most commonly VIth cranial nerve palsies (22\%), followed by hemiplegia ( $20 \%)$, VIIth cranial nerve palsy $7 \%$, paraplegia $6 \%$, monoparesis $4 \%$, IIIrd cranial nerve palsy $4 \%$, optic nerve atrophy $3 \%$, and quadriparesis $2 \%$. Four patients (4\%) were lost to follow up after 3 months of treatment.

\section{Cerebrospinal fluid results}

Lumbar puncture was performed on all patients $(n=$ $100)$ at referring hospitals; 22 (22 \%) children had repeat lumbar puncture at PNT. All CSF was analyzed for protein, lactate and glucose concentrations, and for cell count and differentials (Table 2). The median white cell count was 202 cells/uL. 92 of 95 (97\%) patients had lymphocyte predominance $(>50 \%)$. The mean CSF:blood glucose ratio was 0.25 (range 0.07 to $0.69 ; 7$ of 100 patients had ratios $>0.5$ ). 77 patients had CSF lactate measured; the median was $5.3 \mathrm{mmol} / \mathrm{L}$ (10th and $90^{\text {th }}$ centiles 2.36 and $8.8 \mathrm{mmol} / \mathrm{L}$ respectively). All but 8 patients had elevated CSF protein concentrations (median $1.2 \mathrm{~g} / \mathrm{L}$, upper limit of the normal range $0.4 \mathrm{~g} / \mathrm{L}$ ).

\section{Microbiology results}

None of 22 CSF samples taken at PNT were AFB smear positive, However, M. tuberculosis was cultured from 6 of these samples. Smears of sputum and gastric aspirates were positive for AFB in only $2(7 \%)$ of 29 patients and 5 (7\%) of 67 patients, respectively. Drug susceptibility testing was not performed.

\section{TBM classification}

Six cases met the definition of definite TBM. Sixty-six cases fulfilled the case definition of probable TBM: seven had positive AFB smears and/or M. tuberculosis cultured from sputum or gastric aspirate; 33 had abnormal chest $\mathrm{X}$-rays consistent with $\mathrm{TB}$ and an abnormal brain imaging, and 26 cases had an abnormal CT or MRI brain imaging consistent with TBM. 
Table 2 Baseline characteristics of possible TBM and definite/probable TBM

\begin{tabular}{|c|c|c|c|}
\hline Variables & Possible TBM $(n=28)$ & Definite/Probable TBM $(n=72)$ & $P$-value for comparison \\
\hline $\mathrm{Age}^{\mathrm{a}}$ (months) & $24.5(2-165)$ & $36.5(2-180)$ & 0.09 \\
\hline Male (\%) & 18/28 (64 \%) & 38/72 (53 \%) & 0.03 \\
\hline Fever & 28/28 (100 \%) & 71/72 (99 \%) & 0.99 \\
\hline Symptom duration ${ }^{a}$ (days) & $16(6-60)$ & $19.5(6-96)$ & 0.172 \\
\hline Vomiting & 20/28 (71 \%) & $56 / 72(78 \%)$ & 0.50 \\
\hline Altered sensorium & 6/28 (21\%) & $36 / 72(50 \%)$ & 0.01 \\
\hline Fits & 9/28 (32 \%) & 30/72 (40 \%) & 0.38 \\
\hline Neck stiffness & 17/28 (61 \%) & 58/72 (81 \%) & 0.04 \\
\hline Motor deficit & 4/25 (16 \%) & 28/60 (47 \%) & 0.01 \\
\hline Cranial nerve palsy & 9/28 (32\%) & 18/72 (25\%) & 0.91 \\
\hline HIV infection & $1 / 28(4 \%)$ & 3/72 (4 \%) & 0.99 \\
\hline HBV infection & $2 / 28(7 \%)$ & 3/72 (4 \%) & 0.86 \\
\hline Family TB history & 7/28 (25 \%) & 19/72 (26 \%) & 0.89 \\
\hline Death & $2 / 27^{b}(7 \%)$ & $13 / 69(19 \%)^{c}$ & 0.28 \\
\hline Permanent sequelae & 2/25 (8 \%) & 25/56 (45 \%) & 0.002 \\
\hline CSF WCC & $144(4-780)$ & $150(1-802)$ & 0.37 \\
\hline CSF Lymph ${ }^{a}$ (cells/uL) & $80(40-100)$ & $80 \%(50-100)$ & 0.44 \\
\hline CSF Protein ${ }^{a}(g / L)$ & $0.8(0.2-5)$ & $1.3(0.1-4.8)$ & 0.08 \\
\hline CSF Lactate ${ }^{\mathrm{a}}(\mathrm{mmol} / \mathrm{L})$ & $4.3(1.4-8.8)$ & $5.6(1.21-19.2)$ & 0.08 \\
\hline CSF: Blood Glucose ratio ${ }^{a}$ & $0.30(0.09-0.61)$ & $0.25(0.07-0.69)$ & 0.51 \\
\hline
\end{tabular}

${ }^{a}$ Values are medians/ranges

$\mathrm{b}_{1}$ lost to follow-up

c3 lost to follow-up

The remaining 28 cases fulfilled the definition of possible TBM, with clinical features and CSF biochemistry consistent with the diagnosis. The differences in baseline characteristics and outcome between definite/probable and possible cases are illustrated in Table 2. There were statistically significant lower rates of altered sensorium, neck stiffness and motor deficits at baseline, and a reduced risk of neurological sequelae in possible cases, suggesting that these patients may have had less severe disease.

\section{Imaging findings}

All children had chest X-ray examinations at admission: $42 \%(42 / 100)$ had abnormalities consistent with TB (14\% mediastinal lymphadenopathy $14 \%$, consolidation $11 \%$, miliary pattern $9 \%$, nodules $6 \%$, cavity $1 \%$ and atelectasis $1 \%$ ).

Forty-three patients underwent cranial MRI before beginning treatment (42 with contrast enhancement). Findings are shown in Table 3.

Abnormalities were frequent, detected in $86 \%$ of patients: $62 \%(26 / 42)$ had basal meningeal enhancement, $44 \%(19 / 43)$ hydrocephalus, $30 \%$ (13/43) infarctions and $14 \%(6 / 42)$ tuberculomas. 35 of these 43 patients had repeat cranial MRI scans performed 60 days post randomization: $37 \%(13 / 35)$ had basal meningeal enhancement, $29 \%(10 / 35)$ hydrocephalus, $34 \%(12 / 35)$ infarctions and $29 \%(10 / 35)$ tuberculomas.

\section{Death and sequelae}

Fifteen patients died by 8 months (Kaplan-Meier estimate of mortality $15.7 \%$, 95CI: 9.56-24.3\%, 4 patients lost to follow-up). Eight (53 \%) deaths occurred within the first 6 days of treatment; 14 within 45 days of diagnosis. At the end of treatment, six of 81 surviving patients $(7.4 \%)$ were classified with severe disability and 21/81 (26\%) were classified with intermediate disability (Table 1 ).

Baseline predictors associated with increased risk of death or neurological sequelae are shown in Table 4.

More severe BCS was predictive of increased risk of death, as were history of coma, fits, focal neurological deficits and CSF levels of protein, lactate and glucose. The study did not detect a statistically significant association between risk of death and MRC score but this may be due to the low number of children in the study aged $\geq 5$ years. However, there was a consistent increase in the hazard of death as MRC grade worsened. Hydrocephalus, neck stiffness and MRC grade at baseline were associated with an increased risk of the combined endpoint of neurological sequelae or death $(p=0.01)$. Neither brain infarctions nor 
Table 3 Baseline brain MRI scan results for 43 patients

\begin{tabular}{ll}
\hline Finding & Absolute frequency (\%) \\
\hline Any abnormality & $37 / 43(86 \%)$ \\
Meningeal enhancement & $26 / 42(62 \%)$ \\
Basal & $25(60 \%)$ \\
Sylvian Fissure & $16(37 \%)$ \\
Suprasellar cistern & $4(9 \%)$ \\
Hydrocephalus & $19 / 43(44 \%)$ \\
Tuberculoma & $6 / 42(14 \%)$ \\
Infarction & $13 / 43(30 \%)$ \\
Basal Ganglia & $8 / 43(19 \%)$ \\
Cerebral cortex & $3 / 43(7 \%)$ \\
Internal capsule & $1 / 43(2 \%)$ \\
Brain stem & $1 / 43(2 \%)$ \\
\hline
\end{tabular}

basal meningeal enhancement identified on brain imaging were associated with mortality or the combined endpoint.

Two patients developed drug induced liver injury (DILI) according to the classification of antituberculosis drug-induced hepatotoxicity based on the WHO Adverse Drug Reaction Terminology [20]. This occurred at 2 and 4 weeks following treatment initiation. Neither case was infected with Hepatitis B or C virus. In both cases, PZA was discontinued completely and INH and RIF were reintroduced successfully. Both patients survived.

\section{Uniform case definition for tuberculous meningitis}

After this study was designed and recruited, a consensus document was published suggesting criteria to standardize the categorization of TB meningitis as possible, probable or definite, in order to allow comparison of different populations in intervention trials [21]. The criteria are based upon the expert opinion of a number of international experts. We reclassified our patients according to these new criteria, and this resulted in 18 cases moving from the 'probable' diagnosis to the new 'possible' category, and 8 cases moving from our 'possible' category to the new 'probable' category. Following re-categoristaion, male sex was no longer statistically significantly differently distributed between possible and probable/definite cases; altered sensorium, neck stiffness, motor deficit and permanent sequelae remained significantly more common amongst probable and definite cases. Cranial nerve palsies and death became significantly more associated with probable and definite cases.

\section{Discussion}

This study demonstrates the challenges in delivering effective treatment for TBM in children in Vietnam. First, TBM is associated with considerable mortality and morbidity, with a risk of death at the end of treatment of
$15 \%$, and $33 \%$ of survivors having intermediate or severe disability. These figures are similar to those reported from other studies in children, and to the rates of death and disability seen in HIV uninfected adults with TBM in Vietnam, but while in adult disease considerable progress has been made and large studies are on-going, childhood TBM remains a neglected area [11, 13, 2229]. Treatment guidelines for children are largely derived from studies in adults, and although efforts are underway to develop pediatric formulations in appropriate ratios, at the present time dosing schedules are limited by adult fixed dose combination tablets. Randomised controlled trials and pharmacokinetic studies of novel dosing strategies and agents in children are needed to ensure treatment is optimized.

Secondly, the timely instigation of treatment in TBM remains a significant challenge, even in countries such as Vietnam where the burden of TB is high and the diagnosis is at the forefront of clinicians' minds. In this study, the median time from presentation to treatment was 19 days, and $50 \%$ of deaths occurred within the first 6 days of treatment. Earlier instigation of treatment may be able to prevent these deaths. Delays in diagnosis and treatment are likely explained by 3 main factors. First, poverty is a barrier to accessing health care. Since the study Vietnam has made important progress in rolling out free access to healthcare for children under the age of 6 years; however, this is beyond the means of many countries where the TB burden is highest. Secondly, TBM presents in a non-specific manner and it is rare to confirm the diagnosis microbiologically even in high resource settings. In this study, a definitive diagnosis was made in only $6 \%$ of cases. This is partly explained because only $22 \%(22 / 100)$ of patients had a CSF smear and culture, although the study is representative of real world practice. Of note, no patients were CSF smear positive. Most papers report finding AFB in fewer than $20 \%$ of TBM patients [30]. Improving laboratory training and infrastructure, and improving access to WHO endorsed technologies such as the GeneXpert, would potentially reduce this delay but will not alter the fact that clinical specimens from children are limited both by their volume and their paucibacillary nature [31]. An adequate volume of CSF significantly affects the likelihood of confirming the diagnosis [32] and appropriate sampling for TB at other sites should be performed. Moreover, while TB diagnostic tests remain poorly sensitive, increasing the capacity to identify and exclude other central nervous system pathogens is key in giving clinicians the confidence to instigate treatment in a timely manner and will reduce unnecessary prescription of lengthy $\mathrm{TB}$ regimens. Of note, an approach that has shown promise in South African children with TBM, which resulted in a doubling of diagnostic sensitivity, is 
Table 4 Univariate analysis of potential predictors of mortality and neurological sequelae in patients with tuberculous meningitis

\begin{tabular}{|c|c|c|c|c|c|c|}
\hline \multirow[t]{2}{*}{ Characteristic } & \multicolumn{3}{|c|}{ Time to death $(N=100)$} & \multicolumn{3}{|c|}{ Neurological sequelae or death $(N=96)$} \\
\hline & Death/No at risk & HR (95 \% Cl) & $P$ & Events/No at risk & OR $(95 \% \mathrm{Cl})$ & $P$ \\
\hline \multicolumn{7}{|l|}{ Sex } \\
\hline${ }^{\mathrm{a}}$ Male & 10/56 (17.9 \%) & 0.61 & 0.36 & 23/54 (42.6\%) & 1.11 & 0.80 \\
\hline Female & $5 / 44(11.4 \%)$ & $(0.21-1.78)$ & & 19/42 (45.2 \%) & $(0.49-2.52)$ & \\
\hline \multicolumn{7}{|l|}{ Age } \\
\hline${ }^{a}<5$ years & $11 / 67(16.5 \%)$ & 0.70 & 0.54 & 30/64 (46.9 \%) & 0.68 & 0.38 \\
\hline$\geq 5$ years & 4/33 (12.1\%) & $(0.22-2.20)$ & & 12/32 (37.5 \%) & $(0.28-1.61)$ & \\
\hline \multicolumn{2}{|c|}{ Duration of symptoms $N=89$} & 1.00 & 0.4 & - & 1.01 & 0.43 \\
\hline \multicolumn{2}{|l|}{ (per +1 day) } & $(0.98-1.01)$ & & & $(0.98-1.04)$ & \\
\hline \multicolumn{7}{|l|}{ Neck stiffness } \\
\hline${ }^{\mathrm{a}}$ No & $1 / 25(4.0 \%)$ & 5.15 & 0.11 & 5/24 (20.8\%) & 4.02 & 0.01 \\
\hline Yes & 14/75 (18.7 \%) & $(0.68-39.16)$ & & $37 / 72(51.4 \%)$ & $(1.44-13.18)$ & \\
\hline \multicolumn{7}{|c|}{ HIV co-infection } \\
\hline${ }^{\mathrm{a}}$ No & 13/92 (14.1\%) & 1.85 & 0.55 & 39/88 (44.3 \%) & 0.42 & 0.43 \\
\hline Yes & 1/4 (25.0 \%) & $(0.24-14.17)$ & & 1/4 (25.0 \%) & $(0.02-3.42)$ & \\
\hline \multicolumn{7}{|l|}{ BCS Grade } \\
\hline \multicolumn{7}{|l|}{ age $<5$ years } \\
\hline${ }^{\mathrm{a}} \mathrm{Bl}$ & 0/43 (0 \%) & 1.00 & $<0.001$ & $10 / 40(25.0 \%)$ & 1.00 & $<0.001$ \\
\hline \multirow[t]{2}{*}{ Bll } & $3 / 12(25.0 \%)$ & $27.96^{b}$ & & 9/12 (75.0 \%) & 9.00 & \\
\hline & & $(2.71-3760)$ & & & $(2.21-47.06)$ & \\
\hline \multirow[t]{2}{*}{ BIII } & 8/12 (67.0 \%) & $94.64^{b}$ & & 11/12 (91.7 \%) & 33.00 & \\
\hline & & $(11.71-12,260)$ & & & $(5.44-643.12)$ & \\
\hline \multicolumn{7}{|l|}{ TBM grade } \\
\hline \multicolumn{7}{|l|}{ (age $\geq 5$ years) } \\
\hline al & 1/16 (6.3 \%) & 1.00 & 0.28 & 2/15 (13.3\%) & 1.00 & 0.01 \\
\hline \multirow[t]{2}{*}{$\|$} & 1/11 (9.1 \%) & 1.41 & & 5/11 (45.5 \%) & 5.41 & \\
\hline & & $(0.09-22.5)$ & & & $(0.81-36)$ & \\
\hline \multirow[t]{2}{*}{ III } & 2/6 (33.3 \%) & 6.26 & & 5/6 (83.3 \%) & 32.5 & \\
\hline & & $(0.57-69.2)$ & & & $(2.4-443)$ & \\
\hline \multicolumn{7}{|l|}{ Convulsions } \\
\hline${ }^{\mathrm{a}} \mathrm{No}$ & $5 / 61(8.2 \%)$ & 3.46 & 0.02 & 20/59 (33.9\%) & 2.86 & 0.01 \\
\hline Yes & 10/39 (25.6\%) & $(1.18-10.13)$ & & 22/37 (59.5\%) & $(1.24-6.81)$ & \\
\hline \multicolumn{7}{|c|}{ Decreased level of consciousness } \\
\hline${ }^{\mathrm{a}} \mathrm{No}$ & $1 / 58(1.7 \%)$ & 22.9 & $<0.001$ & 10/54 (18.5 \%) & 14.08 & $<0.001$ \\
\hline Yes & 14/42 (33.3 \%) & $(3.01-174.3)$ & & $32 / 42(76.2 \%)$ & $(5.46-39.85)$ & \\
\hline \multicolumn{7}{|c|}{ Focal neurological deficits } \\
\hline${ }^{\mathrm{a}} \mathrm{No}$ & 0/53 (0 \%) & 15.66 & 0.01 & $6 / 50(12.0 \%)$ & 15.4 & $<0.001$ \\
\hline Yes & 4/32 (12.5\%) & $(1.67-2075)$ & & 21/31 (67.7\%) & $(5.22-51.96)$ & \\
\hline \multicolumn{7}{|c|}{ Extra meningeal TB } \\
\hline${ }^{\mathrm{a}} \mathrm{No}$ & $6 / 51(11.8 \%)$ & 2.3 & 0.11 & 19/57 (33.3\%) & 2.87 & 0.01 \\
\hline Yes & 9/30 (30.0\%) & $(0.82-6.45)$ & & 23/39 (59.0 \%) & $(1.25-6.80)$ & \\
\hline \multicolumn{7}{|l|}{ TB culture } \\
\hline${ }^{a}$ Negative & 2/14 (14.3\%) & 2.72 & 0.33 & 4/16 (25.0\%) & 4.50 & 0.16 \\
\hline
\end{tabular}


Table 4 Univariate analysis of potential predictors of mortality and neurological sequelae in patients with tuberculous meningitis (Continued)

\begin{tabular}{|c|c|c|c|c|c|c|}
\hline Positive & 2/3 (66.7 \%) & $(0.38-19.4)$ & & $3 / 5(60.0 \%)$ & $(0.56-45.4)$ & \\
\hline \multicolumn{7}{|l|}{ Hydrocephalus ${ }^{c}$} \\
\hline${ }^{\mathrm{a}} \mathrm{No}$ & 2/31 (6.5 \%) & 3.46 & 0.10 & 6/31 (19.4 \%) & 9.72 & $<0.001$ \\
\hline Yes & 6/30 (20.0 \%) & $(0.70-17.16)$ & & 21/30 (70.0 \%) & $(2.97-32)$ & \\
\hline \multicolumn{7}{|l|}{ Cranial nerve palsy } \\
\hline No & 14/70 (20.0 \%) & 5.42 & 0.10 & 29/70 (41.4 \%) & 0.71 & 0.45 \\
\hline Yes & 1/26 (3.8 \%) & $(0.71-42.2)$ & & 13/26 (50.0 \%) & $(0.29-1.75)$ & \\
\hline CSF Protein & $N=99$ & 1.74 & 0.002 & $N=94$ & 1.65 & 0.01 \\
\hline (per + 1 g/L) & & $(1.22-2.49)$ & & & $(1.14-2.51)$ & \\
\hline CSF Lactate & $N=77$ & 1.14 & 0.04 & $N=73$ & 1.20 & 0.03 \\
\hline$($ per $+1 \mathrm{mmol} / \mathrm{L})$ & & $(1.01-1.29)$ & & & $(1.01-1.47)$ & \\
\hline CSF Glucose & $N=100$ & 0.45 & 0.05 & $N=96$ & 0.65 & 0.10 \\
\hline$($ per $+1 \mathrm{mmol} / \mathrm{L})$ & & $(0.20-0.98)$ & & & $(0.38-1.08)$ & \\
\hline
\end{tabular}

${ }^{a}$ Baseline category. HR and OR give comparisons to the baseline category. P-value is an overall likelihood ratio test for the significance of the factor

${ }^{b}$ Model fitted by logistic regression with Firth correction

chydrocephalus diagnosed by MRI brain (43 patients or CT brain 19 patients)

the use of more than one nucleic acid amplification test on CSF [33]. However, the investigators still found a combination of microscopy and culture to be most effective. We have found GeneXPert and CSF smear to have similar sensitivities of in adult patients; the challenge for Vietnam remains in obtaining significant volumes of CSF from infants and balancing the risk of investigation with the benefits of a definitive diagnosis [31]. The early identification of drug resistance is likely to be an important factor in improving outcomes. A South African study found that drug resistance was associated with delays in instigation of effective treatment, and that multidrug resistance was associated with worse outcomes [34]. In this study isoniazid mono-resistance was not clearly associated with worse outcomes [34]. However, this mimics the experience in adult patients initial small studies failed to show a deleterious effect of isoniazid mono-resistance on outcome, but later larger datasets demonstrated that indeed such resistance is disadvantageous $[35,36]$.

Thirdly, TB treatment is onerous, both in regards to side effects and duration, which may lead to reluctance to start empirical treatment where the risk and consequences of disease are perceived to be low. However, $M$. tuberculosis has been reported to be a more frequent cause of meningitis than pyogenic organisms in South Africa - given that $50 \%$ of deaths are occurring within the first week of treatment a case could be made for early empirical TB treatment in such centres [37]. Few data exist on the optimal duration of treatment for TBM. Drugs such as the fluoroquinolones, which have good tolerability and excellent CSF penetration, potentially offer more effective and palatable treatment regimens, but are relatively untested in children [38]. Randomized controlled trials in children specifically designed to improve TB treatment by 1 ) identifying shorter equally effective courses and 2) new treatment combinations, may go some way to addressing this issue, although recent trials in adult patients have had mixed results [39-42]. The effective dose of rifampicin appears to be key in improving outcomes. Such regimes would enable a move towards an empirical therapeutic approach similar to that used in acute bacterial meningitis to be employed in high burden settings.

Finally, it is reassuring that drug induced liver injury necessitating treatment interruption was rare and not associated with a poor outcome in this study, affecting just $2 \%$ of the patients. Our study is small and thus our estimates are somewhat imprecise. However, the rate is considerably lower than the $13 \%$ quoted for DILI in adults, supporting the concept that higher doses could be used in children, as advocated in the recent WHO guidelines. [2, 43-45].

Our study had some limitations. It was limited by its small size, and thus estimates around the rates of death and other sequelae lack precision, although findings are generally in keeping with other series [13]. Secondly, we used all-cause mortality. However, $50 \%$ of all deaths occurred within 1 week of treatment initiation, and the rates of co-morbidities (such as HIV) were low, meaning that it is reasonable to assume that all deaths were either a direct consequence of TB or a result of its sequelae. Thirdly, children were only followed up until the end of treatment, and we may have missed later deaths and relapse. The main limitation is the low rate of microbiological confirmation of tuberculosis. This is consistent 
with other studies in children and represents the very real practical difficulties of managing these children. It is possible that some of these cases, particularly those meeting the 'possible' case definition, may have had some other pathology. However, when the possible cases are excluded, then the mortality and morbidity rate rises further underlying the need to improve diagnostics and treatment for this devastating disease.

Our study was designed and completed before the publication of the universal case definition (UCD) for TBM was published and thus we present our results as originally intended, with a secondary analysis using this classification [21]. The UCD is based upon a non-linear scoring system derived from expert opinion, and has been shown to misclassify $14 \%$ of cases of culture proven TBM as possible TBM in children in a South African study [46]. This underlines the danger of using this research tool as a diagnostic aid, particularly where microbiological diagnostic facilities are poorly developed. Moreover, it is not yet clear that the UCD achieves that which it set out to achieve - i.e allowing robust comparison of patients across diverse study groups according to the UCD defined likelihood of there being definite, probable or possible TBM. As an illustration, a study from South Africa found that patients with 'possible' versus other 'probable/definite' TBM had significant differences in CSF protein concentrations and CSF/serum glucose concentrations. This difference was not apparent in our children, suggesting that our 'possible' cases may be more likely to actually have TBM than possible cases from South African series [47]. There is a need to develop more robust data-driven classification systems, and given the number of patients enrolled into intervention trials in the last 15 years this should be feasible $[11,15,38,48]$.

\section{Conclusions}

Tuberculous meningitis in children carries significant morbidity and mortality in Vietnam. A particular challenge is in reducing the time to diagnosis, and institution of effective treatment. However, improving outcomes will also require the development of treatment regimens tailored to children. Given the recent disappointing results of fluoroquinolone boosted treatment regimens in adults with TBM, randomized controlled trials of boosted rifampicin dosing would seem the most important strategy to develop.

\footnotetext{
Abbreviations

AFB: Acid fast bacilli; BCS: Blantyre coma score; CSF: Cerebrospinal fluid; DILI: Drug induced liver injury; DOT: Directly observed treatment; E: Ethambutol; GCS: Glasgow coma score; H: Isoniazid; HCMC: Ho Chi Minh City; HIV: Human immunodeficiency virus; INH: Isoniazid; MRC: Medical Research Council; MRI: Magnetic Resonance Imaging; PNT: Pham Ngoc Thach Hospital; PZA: Pyrazinamide; R: Rifampicin; RIF: Rifampicin; S: Streptomycin; TB: Tuberculosis; TB: Tuberculosis; TBM: Tuberculous meningitis; UK: United Kingdom; WHO: Word Health Organisation; Z: Isoniazid
}

\section{Acknowledgements}

We thank the study participants, their parents, and the ward, administrative and laboratory staff of PNT, and the funders for making this study possible.

\section{Funding}

Funded by the Wellcome Trust UK. JND is a Wellcome Trust Intermediate Fellow Grant No WT097147MA.

\section{Availability of data and materials}

The ethical approval and consent procedures did not include permission to make the raw data available for public dissemination since this was not practice at the time of the study.

\section{Authors' contributions}

JND, TP, NDB and JF designed the study; NDB, JND, TND, NHD, PVT, DTMH, MC, LM and TP generated the data; NDB, JND, TाT and MW analysed the results; JND wrote the first draft of the manuscript; all authors reviewed and edited the manuscript. All authors read and approved the final manuscript.

\section{Competing interests}

The authors declare that they have no competing interests.

\section{Ethics approval and consent to participate}

The study received ethical approval from the ethical review board of Pham Ngoc Thach Hospital, Viet Nam, the Health Services of Ho Chi Minh City and the Oxford University Tropical Ethics Committee, UK. Written informed consent was obtained from the parents or guardians of all participants, and assent from all children with capacity.

\section{Author details}

'Oxford University Clinical Research Unit, Wellcome Trust Major Overseas Programme, 764 Vo Van Kiet, Quan 5, Ho Chi Minh City, Vietnam. ${ }^{2}$ Pham Ngoc Thach Hospital, 120 Hung Vuong, Quan 5, Ho Chi Minh City, Vietnam. ${ }^{3}$ Department of Clinical Sciences, Liverpool School of Tropical Medicine, Pembroke Place, L3 5QA Liverpool, UK. ${ }^{4}$ Centre for Tropical Medicine and Global Health, Nuffield Department of Medicine Research Building, University of Oxford, Old Road campus, Roosevelt Drive, Oxford, UK. ${ }^{5}$ Mahidol-Oxford Tropical Medicine Research Unit, Faculty of Tropical Medicine, 420/6 Ratchawithi Rd., Bangkok, Thailand.

Received: 15 March 2016 Accepted: 12 October 2016

Published online: 18 October 2016

References

1. Cruz AT, Starke JR. What's in a number? Accurate estimates of childhood tuberculosis. The Lancet Global Health. 2014;2(8):e432-3.

2. WHO. Guidance for national tuberculosis programmes on the management of tuberculosis in children second edition. 2nd ed. Geneva: WHO; 2014.

3. Dodd PJ, Gardiner E, Coghlan R, Seddon JA. Burden of childhood tuberculosis in 22 high-burden countries: a mathematical modelling study. The Lancet Global Health. 2014;2(8):e453-9.

4. Thwaites GE, van Toorn R, Schoeman J. Tuberculous meningitis: more questions, still too few answers. Lancet Neurol. 2013;12(10):999-1010.

5. Beyers N, Gie RP, Schaaf HS, Van Zyl S, Talent JM, Nel ED, Donald PR. A prospective evaluation of children under the age of 5 years living in the same household as adults with recently diagnosed pulmonary tuberculosis. Int J Tuberc Lung Dis. 1997;1(1):38-43.

6. Marais BJ, Gie RP, Schaaf HS, Hesseling AC, Obihara CC, Starke JJ, Enarson DA, Donald PR, Beyers N. The natural history of childhood intra-thoracic tuberculosis: a critical review of literature from the pre-chemotherapy era. Int J Tuberc Lung Dis. 2004;8(4):392-402.

7. Kent SJ, Crowe SM, Yung A, Lucas CR, Mijch AM. Tuberculous meningitis: a 30-year review. Clin Infect Dis. 1993;17(6):987-94.

8. Cuevas LE, Browning R, Bossuyt P, Casenghi M, Cotton MF, Cruz AT, Dodd LE, Drobniewski F, Gale M, Graham SM, et al. Evaluation of tuberculosis diagnostics in children: 2. Methodological issues for conducting and reporting research evaluations of tuberculosis diagnostics for intrathoracic tuberculosis in children. Consensus from an expert panel. J Infect Dis. 2012; 205 Suppl 2:S209-15.

9. Ertekin V, Alp H, Altinkaynak S, Selimoglu MA. Tuberculous meningitis in Turkish children: an evaluation of 38 cases. Trop Doct. 2005;35(3):183-4. 
10. Mihailidou E, Goutaki M, Nanou A, Tsiatsiou O, Kavaliotis J. Tuberculous meningitis in Greek children. Scand J Infect Dis. 2012;44(5):337-43.

11. Thwaites GE, Nguyen DB, Nguyen HD, Hoang TQ, Do TT, Nguyen TC, Nguyen QH, Nguyen TT, Nguyen NH, Nguyen TN, et al. Dexamethasone for the treatment of tuberculous meningitis in adolescents and adults. N Engl J Med. 2004:351(17):1741-51.

12. The Lancet $\mathrm{N}$. Tuberculosis of the CNS remains a lethal threat. Lancet Neurol. 2011;10(5):395

13. Chiang SS, Khan FA, Milstein MB, Tolman AW, Benedetti A, Starke JR, Becerra MC. Treatment outcomes of childhood tuberculous meningitis: a systematic review and meta-analysis. Lancet Infect Dis. 2014;14(10):947-57.

14. Hoa NB, Sy DN, Nhung NV, Tiemersma EW, Borgdorff MW, Cobelens FG. National survey of tuberculosis prevalence in Viet Nam. Bull World Health Organ. 2010;88(4):273-80

15. Torok ME, Yen NT, Chau TT, Mai NT, Phu NH, Mai PP, Dung NT, Chau NV, Bang ND, Tien NA, et al. Timing of initiation of antiretroviral therapy in human immunodeficiency virus (HIV)-associated tuberculous meningitis. Clin Infect Dis. 2011;52(11):1374-83.

16. Heemskerk D, Day J, Chau TTH, Dung NH, Yen NTB, Bang ND, Merson L, Olliaro P, Pouplin T, Caws M, et al. Intensified treatment with high dose Rifampicin and Levofloxacin compared to standard treatment for adult patients with Tuberculous Meningitis (TBM-IT): protocol for a randomized controlled trial. Trials. 2011;12:25.

17. Torok ME, Chau TT, Mai PP, Phong ND, Dung NT, Chuong LV, Lee SJ, Caws $\mathrm{M}$, de Jong MD, Hien TT, et al. Clinical and microbiological features of HIVassociated tuberculous meningitis in Vietnamese adults. PLoS One. 2008; 3(3):e1772.

18. Heinze $G$, Schemper M. A solution to the problem of separation in logistic regression. Stat Med. 2002;21(16):2409-19.

19. R: A language and environment for statistical computing. [http://www.Rproject.org]. Accessed 13 Oct 2016

20. Tostmann A, Boeree MJ, Aarnoutse RE, de Lange WC, van der Ven AJ, Dekhuijzen R. Antituberculosis drug-induced hepatotoxicity: concise up-todate review. J Gastroenterol Hepatol. 2008;23(2):192-202.

21. Marais S, Thwaites G, Schoeman JF, Torok ME, Misra UK, Prasad K, Donald PR, Wilkinson RJ, Marais BJ. Tuberculous meningitis: a uniform case definition for use in clinical research. Lancet Infect Dis. 2010;10(11):803-12.

22. Farinha NJ, Razali KA, Holzel H, Morgan G, Novelli VM. Tuberculosis of the central nervous system in children: a 20-year survey. J Infect. 2000;41(1):61-8.

23. Yaramis A, Gurkan F, Elevli M, Soker M, Haspolat K, Kirbas G, Tas MA. Central nervous system tuberculosis in children: a review of 214 cases. Pediatrics. 1998;102(5):E49.

24. Paganini H, Gonzalez F, Santander C, Casimir L, Berberian G, Rosanova MT. Tuberculous meningitis in children: clinical features and outcome in 40 cases. Scand J Infect Dis. 2000;32(1):41-5.

25. Girgis NI, Sultan Y, Farid Z, Mansour MM, Erian MW, Hanna LS, Mateczun AJ. Tuberculosis meningitis, Abbassia Fever Hospital-Naval Medical Research Unit No. 3-Cairo, Egypt, from 1976 to 1996. Am J Trop Med Hyg. 1998;58(1):28-34.

26. Doerr CA, Starke JR, Ong LT. Clinical and public health aspects of tuberculous meningitis in children. J Pediatr. 1995;127(1):27-33.

27. Delage G, Dusseault M. Tuberculous meningitis in children: a retrospective study of 79 patients, with an analysis of prognostic factors. Can Med Assoc J. 1979;120(3):305-9.

28. Kumar R, Dwivedi A, Kumar P, Kohli N. Tuberculous meningitis in BCG vaccinated and unvaccinated children. J Neurol Neurosurg Psychiatry. 2005; 76(11):1550-4

29. van Well GT, Paes BF, Terwee CB, Springer P, Roord JJ, Donald PR, van Furth AM, Schoeman JF. Twenty years of pediatric tuberculous meningitis: a retrospective cohort study in the western cape of South Africa. Pediatrics. 2009;123(1):e1-8.

30. Garg RK. Tuberculosis of the central nervous system. Postgrad Med J. 1999 75(881):133-40.

31. Nhu NT, Heemskerk D, Thu do DA, Chau TT, Mai NT, Nghia HD, Loc PP, Ha DT, Merson L, Thinh TT, et al. Evaluation of GeneXpert MTB/RIF for diagnosis of tuberculous meningitis. J Clin Microbiol. 2014;52(1):226-33.

32. Thwaites GE, Chau TT, Farrar JJ. Improving the bacteriological diagnosis of tuberculous meningitis. J Clin Microbiol. 2004;42(1):378-9.

33. Solomons RS, Visser DH, Friedrich SO, Diacon AH, Hoek KG, Marais BJ, Schoeman JF, van Furth AM. Improved diagnosis of childhood tuberculous meningitis using more than one nucleic acid amplification test. Int J Tuberc Lung Dis. 2015;19(1):74-80.
34. Seddon JA, Visser DH, Bartens $M$, Jordaan AM, Victor TC, van Furth AM, Schoeman JF, Schaaf HS. Impact of drug resistance on clinical outcome in children with tuberculous meningitis. Pediatr Infect Dis J. 2012;31(7):711-6.

35. Tho DQ, Torok ME, Yen NT, Bang ND, Lan NT, Kiet VS, van Vinh CN, Dung $\mathrm{NH}$, Day J, Farrar J, et al. Influence of antituberculosis drug resistance and Mycobacterium tuberculosis lineage on outcome in HIV-associated tuberculous meningitis. Antimicrob Agents Chemother. 2012;56(6):3074-9.

36. Thwaites GE, Lan NT, Dung NH, Quy HT, Oanh DT, Thoa NT, Hien NQ, Thuc $N T$, Hai NN, Bang ND, et al. Effect of antituberculosis drug resistance on response to treatment and outcome in adults with tuberculous meningitis. J Infect Dis. 2005;192(1):79-88.

37. Wolzak NK, Cooke ML, Orth H, van Toorn R. The changing profile of pediatric meningitis at a referral centre in Cape Town, South Africa. J Trop Pediatr. 2012;58(6):491-5

38. Thwaites GE, Bhavnani SM, Chau TT, Hammel JP, Torok ME, Van Wart SA Mai PP, Reynolds DK, Caws M, Dung NT, et al. Randomized pharmacokinetic and pharmacodynamic comparison of fluoroquinolones for tuberculous meningitis. Antimicrob Agents Chemother. 2011;55(7):3244-53.

39. Alvarez-Uria G, Midde M, Pakam R, Naik PK. Initial antituberculous regimen with better drug penetration into cerebrospinal fluid reduces mortality in HIV infected patients with tuberculous meningitis: data from an HIV observational cohort study. Tuberc Res Treat. 2013:2013:242604.

40. Ruslami R, Ganiem AR, Dian S, Apriani L, Achmad TH, van der Ven AJ, Borm $\mathrm{G}$, Aarnoutse RE, van Crevel R. Intensified regimen containing rifampicin and moxifloxacin for tuberculous meningitis: an open-label, randomised controlled phase 2 trial. Lancet Infect Dis. 2013;13(1):27-35.

41. Te Brake L, Dian S, Ganiem AR, Ruesen C, Burger D, Donders R, Ruslami R, van Crevel R, Aarnoutse R. Pharmacokinetic/pharmacodynamic analysis of an intensified regimen containing rifampicin and moxifloxacin for tuberculous meningitis. Int J Antimicrob Agents. 2015:45(5):496-503.

42. Heemskerk AD, Bang ND, Mai NT, Chau TT, Phu NH, Loc PP, Chau NV, Hien TT, Dung NH, Lan NT, et al. Intensified antituberculosis therapy in adults with tuberculous meningitis. N Engl J Med. 2016:374(2):124-34.

43. Baghaei P, Tabarsi P, Chitsaz E, Saleh M, Marjani M, Shemirani S, Pooramiri MV, Kazempour M, Farnia P, Fahimi F, et al. Incidence, clinical and epidemiological risk factors, and outcome of drug-induced hepatitis due to antituberculous agents in new tuberculosis cases. Am J Ther. 2010;17(1):17-22.

44. Tariq S, Khan TS, Malik S, Anwar MS, Rashid A. Frequency of anti-tuberculous therapy-induced hepatotoxicity in patients and their outcome. J Ayub Med Coll Abbottabad. 2009;21(4):50-2.

45. Altman C, Biour M, Grange JD. Hepatic toxicity of antitubercular agents. Role of different drugs. 199 cases. Presse Med. 1993;22(26):1212-6.

46. Solomons RS, Wessels M, Visser DH, Donald PR, Marais BJ, Schoeman JF, van Furth AM. Uniform research case definition criteria differentiate tuberculous and bacterial meningitis in children. Clin Infect Dis. 2014;59(11):1574-8.

47. Solomons RS, Visser DH, Donald PR, Marais BJ, Schoeman JF, van Furth AM. The diagnostic value of cerebrospinal fluid chemistry results in childhood tuberculous meningitis. Childs Nerv Syst. 2015:31(8):1335-40.

48. Heemskerk AD, Bang ND, Mai NT, Chau TT, Phu NH, Loc PP, Chau NV, Hien TT, Dung NH, Lan NT, et al. Intensified antituberculosis therapy in adults with tuberculous meningitis. N Engl J Med. 2016;374(2):124-34.

\section{Submit your next manuscript to BioMed Central and we will help you at every step:}

- We accept pre-submission inquiries

- Our selector tool helps you to find the most relevant journal

- We provide round the clock customer support

- Convenient online submission

- Thorough peer review

- Inclusion in PubMed and all major indexing services

- Maximum visibility for your research

Submit your manuscript at www.biomedcentral.com/submit 